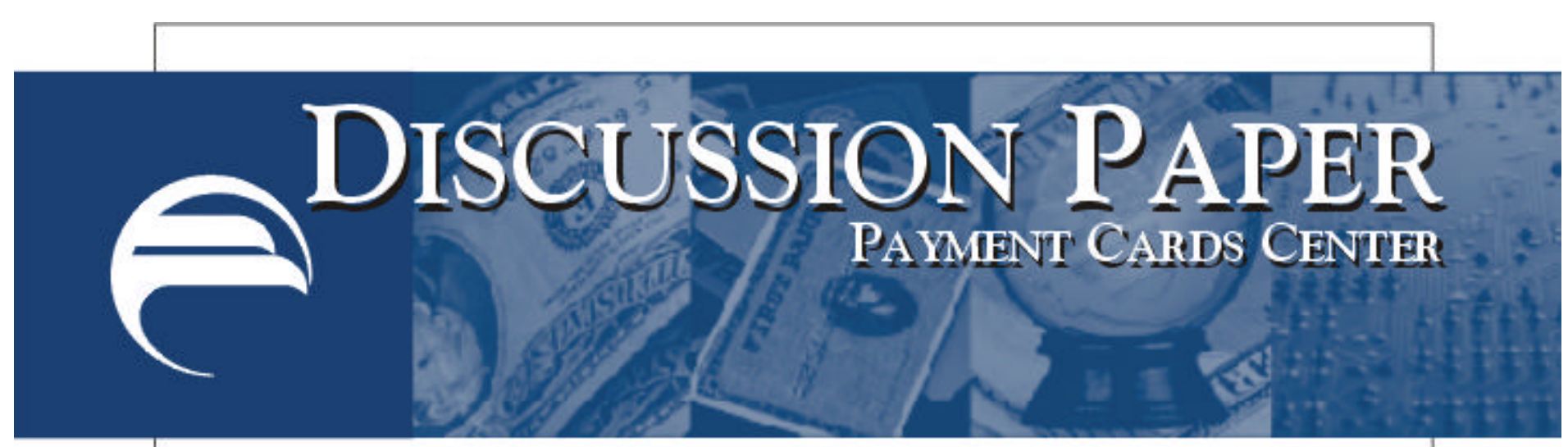

\title{
Retail Credit Risk Modeling and the Basel Capital Accord ${ }^{1}$
}

\author{
Peter Burns
}

January 2002

Summary: On December 14, 2001, the Payment Cards Center of the Federal Reserve Bank of Philadelphia held a workshop exploring retail credit risk modeling practices and evolving techniques. The workshop was led by Paul Calem, a senior economist at the Board of Governors, Division of Research and Statistics. Calem is currently involved in the Board's efforts supporting reforms to the international Basel Capital Accord intended to refine risk-based bank capital standards. ${ }^{2}$ Existing credit risk modeling practices in the banking industry are being evaluated by the international regulatory community in the context of developing an internal ratings-based (IRB) approach to capital requirements. While the broader effort encompasses both wholesale and retail lending, Calem's comments and the workshop discussion focused specifically on the retail sector. As credit card outstandings have become the fastest growing proportion of consumer debt, the application of risk assessment models to regulatory capital requirements is a particularly relevant issue for the Payment Cards Center. This paper provides highlights from Calem's presentation and the ensuing discussion and is complemented by additional background information on the Basel Accord and industry capital allocation practices.

${ }^{1}$ The views expressed here are not necessarily those of this Reserve Bank or of the Federal Reserve System.

${ }^{2}$ Dr. Calem's broader research interests include issues related to bank capital regulation, credit card lending, competitive performance in banking markets, and fair lending practices.

\section{Federal Reserve Bank of Philadelphia}




\section{Basel Capital Accord and Credit Risk Quantification}

The original 1988 Basel Capital Accord was based on a highly simplified credit risk classification of bank assets. Assets were grouped into one of four broad risk classes for assigning regulatory capital, and the capital required for each risk-weighted category of loans was summed to determine a minimum level of required capital for the bank as a whole. While several types of bank loans (most notably, home mortgages) received different risk weightings, the bulk of a typical bank's loans were deemed to require an 8 percent allocation of total capital (4 percent tier-one capital) as a solvency cushion. As such, loans in relatively stable credit card portfolios; for example, are assessed the same capital requirement as loans in more volatile commercial real estate portfolios. Moreover, loans within a given class are similarly judged to be of equal risk so that AAA corporate credits carry the same regulatory capital requirement as loans to BBB borrowers.

While bank regulators worked to implement the early Basel Accord, a number of banks were developing internal models to independently determine their own needs for economic capital in support of their risk-taking activities. These models attempted to address not only the risk differences among loan classes but also — particularly on the wholesale side — differences in the risks of individual loans within a class. For many banks with relatively conservative lending activities, the resulting internally generated capital requirements often fell below the regulatory minimums. As these gaps emerged, the opportunity for "regulatory capital arbitrage" arose. As such, banks with internal assessments that called for less capital than required by regulation might be tempted to "arbitrage" this difference by taking on more risky loans at the margin. 
Faced with at least the potential for these unintended consequences, regulators have worked to refine the original Basel Accord to incorporate more refined risk-weighted approaches to capital assessment. For those institutions with sophisticated IRB approaches to quantifying credit risk, the intent is to map an exposure's internal rating into a regulatory capital requirement that is calibrated to reflect the underlying credit risk. For those banks without adequate credit risk quantification methods, a regulatory standardized risk-weighting approach will apply.

In Calem's view, mapping the measured risk characteristics (probability of default and loss-given-default) associated with a particular internal rating into a regulatory capital assignment represents a significant challenge to implementing the new IRB approach, particularly for retail assets. He noted the high degree of variability in the way even the most sophisticated institutions translate credit risk characteristics into the calculations that lead to required capital. This is not just a result of the complexity of the task itself; it also reflects inadequacies in the current state of knowledge and experience in these areas.

The Federal Reserve and other regulators are working together with the industry to better understand the adequacy of credit risk quantification methods and the reasonableness of the resulting capital calculations. At the most fundamental level, the goal is to ensure that changes in the new accord serve to promote the safety and soundness of the financial system. An important objective within this context is to create a structure that provides incentives for banks to use more sophisticated risk assessment systems by rewarding IRB approaches with lower total capital requirements than would be calculated by the standard formula approach.

\section{Retail vs. Wholesale Risk Quantification: Wholesale}

While the bulk of the workshop discussion focused on retail credit, Calem began by distinguishing the risk quantification methods generally employed in wholesale versus retail 
lending. In wholesale (corporate) lending, Calem noted that most approaches rely on what are essentially mark-to-market valuation methodologies and models. These sophisticated models benefit from an extensive literature in corporate finance that has provided a strong theoretical underpinning for the evolving approaches but require access to market credit-spread data for valuing portfolios conditional on alternative risk-factor outcomes.

There are substantial differences in the various wholesale models employed, but they generally rely on a single-period framework and simulate migration to default or change in value. The models are generally based on internally derived risk classification schemes, where individual loans are assigned transition probabilities based on market data that represent expectations for default or declines in value over the time period. Correlation of performance outcomes across individual exposures is another key parameter, where the source of correlation is a set of common underlying risk factors. Random realizations of these risk factors lead to correlated changes in default probabilities as reflected in the overall portfolio valuation. The models thus yield a quantification of the degree to which the portfolio is susceptible to large losses in value. Capital can then be allocated to protect the bank, at some determined level, against the low-probability but high-consequence events in the far tail of the loss probability distribution.

\section{Retail vs. Wholesale Risk Quantification: Retail}

Retail lending differs substantially from wholesale lending, and while sophisticated scoring methods are employed for classifying and/or measuring delinquency and default probabilities for individual retail credits, internal economic capital models are less fully developed for retail. There are several reasons why portfolio credit risk modeling has received less attention on the retail side. The industry has long observed that large losses in the corporate 
loan portfolio may not only affect profitability but may often threaten institutional solvency.

With low dollar exposures on individual loans and relatively predictable loss experience on the retail side, most bank risk managers have historically devoted less attention and resources to consumer loan portfolios. Moreover, while the extensive corporate finance literature provides a strong theoretical underpinning for wholesale portfolio credit risk modeling, there is no similar body of theoretical study on the consumer side. Construction of retail mark-to-market type credit risk models is further hindered by lack of data on credit spreads.

Historically, the industry and its regulators have viewed retail portfolios as relatively homogeneous sets of small dollar transactions that might have relatively higher, but largely predictable, expected loss characteristics. Unexpected credit losses from these portfolios were deemed to be relatively low, requiring only modest levels of capital support. By comparison, wholesale lending is viewed as having almost diametrically opposed credit risk characteristics. Corporate loan portfolios generally contain relatively fewer, but significantly larger, transactions with widely varying risk profiles. In this environment, banks generally experience lower expected losses but wide variations around the mean. This leads to a greater probability of large unexpected losses that could threaten capital adequacy and institutional solvency. In this sense, it is no surprise that both regulators and bank risk managers have historically focused risk-based capital allocation methodologies on the corporate side of the balance sheet and paid less attention to retail portfolio credit risks.

While most banks continue to hold this view, the growing relative size and increased volatility of retail portfolios are attracting increased attention from bank risk managers and regulators. Rising absolute levels of consumer and small-business debt have provided sustained loan growth for many banks over the past 20 years, increasing the proportion of retail exposures 
for many institutions. The dramatic growth in unsecured credit card debt over this period is one notable contributor to this phenomenon. Concurrently, the mono-line credit card banks and other specialized retail lenders that evolved during this period were able to develop focused risk management processes without the distraction of also managing complex corporate risk portfolios. In fact, much of the recent advancement in retail credit risk management has come from these specialized institutions and banking counterparts with large retail exposures. The recent consolidation in the credit card industry, for example, has created significantly greater retail exposures for a number of bank lenders active in credit card portfolio acquisitions.

As consumer lenders broadened their marketing efforts in search of new borrowers, they also have altered the risk profiles of what were once relatively static portfolios. The growth in sub-prime lending has added new dynamics to many portfolios and poses challenges to risk managers. While the industry has so far managed the risk environment reasonably well, the spike in personal bankruptcies in the 1996-98 period caught many in the credit card industry off-guard. This, along with the more recently publicized difficulties experienced by several large sub-prime lenders, has provided additional evidence of increased risk. All of which has led to a heightened awareness of the need for more sophisticated retail credit risk management tools and technologies.

\section{Retail Credit Risk Quantification}

There are some similarities, but also important differences, between approaches to credit risk modeling in the wholesale and retail contexts. Unlike most wholesale risk models that are 
based on mark-to-market assessments, retail models, Calem noted, are typically founded on book-value frameworks. As such, losses are recognized only in the event of default, and there is no attempt to recognize changes in the probability-of-default and the resulting impact on portfolio value. In addition to the book-value approach, retail risk models employ a singleperiod (typically, one year) analysis, which further precludes consideration of losses due to changes in probability of default. Thus, for portfolios containing assets with maturity longer than one year, there is no recognition of either value declines due to increased probability of default or losses due to defaults beyond the one-year time frame.

Generally, these models begin with segment definitions created around credit scores. The key predictive parameters for each segment are the expected, or long-run, average probability of default, loss given default, and a default correlation. The latter has a business-cycle interpretation and measures the degree to which one-year default probabilities on individual exposures are determined by common underlying factors that are subject to change. For the resulting portfolio loss distributions, as in the wholesale case, far-tail percentiles are ultimately mapped to desired capital cushions. The typical retail credit risk model is largely formulaic in nature, although some newer approaches incorporate variables tied to macroeconomic factors and generate more robust probability distributions.

Calem discussed a number of issues often encountered with these models. Clearly, if segments are defined too broadly, the parameter estimates are subject to increased error. Distortions can also come into play if "portfolio seasoning" factors are not properly considered when attempting to calibrate key parameters. The age of accounts within a portfolio segment is a 
unique variable in retail risk modeling that can vary considerably between otherwise similar portfolios. Default correlations in these models are generally inferred from a time series of default rates and may be subject to bias if the data do not incorporate a full economic cycle or, even so, if the time-series is short or highly autocorrelated. However, in Calem's view, perhaps the most problematic issue is the inability of the one-period models to fully quantify credit risk for portfolios containing loans with maturities longer than one year.

Looking forward, Calem discussed emerging approaches to the retail risk quantification challenge. Some within the industry are exploring the application of corporate mark-to-market models by mapping corporate weightings to retail risk segments. The principal advantage derived from these models is their ability to provide a forward-looking perspective by capturing valuation dynamics. The fact that these techniques are tied to corporate finance theory and are calibrated in part from corporate data adds a fundamental grounding that, in principle, can be extended in evolving frameworks. Other evolving approaches attempt to incorporate the multiperiod risk view in the book value framework. In these cases, the capital required to maintain a specified solvency probability is calculated as the discounted value of cumulative unexpected loss. Last, new data-intensive methodologies are being developed that predict performance under simulated risk-factor scenarios and generate resulting distributions over portfolio credit losses. These approaches incorporate key economic variables and particular loan and portfolio characteristics, such as loan size and geographic concentration. These data-intensive methodologies have provided some encouraging results, most notably in mortgage lending. However, their usefulness is limited because they require extensive loan-performance databases and complex applications of econometric modeling. 


\section{Conclusions}

In concluding, Calem noted that any economic capital model involves some limiting or unverifiable assumptions and suggested a continuing role for stress testing as a "safety check." While reiterating the need to pay careful attention to potential calibration problems and to develop retail portfolio credit risk models that account for multiyear maturity horizons, he concluded the discussion on a note of optimism. Despite the relative early weaknesses of most IRB approaches in assessing capital requirements for retail lending, the industry is making rapid and substantial progress. As new methods evolve and databases expand, the future of retail credit risk modeling seems promising. In fact, in some sense, retail portfolios are better suited to modeling than their wholesale counterparts. The large number of observations routinely capture in automated processing environments means that the data are available for analysis. The challenge is to effectively organize the data for risk modeling. Meanwhile the Basel staff, taking the limitations discussed here into account, is, at least in part, using credit risk models to calibrate proposed retail credit risk weights for the new regulatory framework. 